\title{
Ceyuan (測圓海鏡) and Jiuyong Yandai (九容演代)
}

\author{
CHENG Chun Chor, Litwin 鄭振初
}

\begin{abstract}
The book 《Ceyuan Haijing》studies inscribed and circumscribed circles in a right triangle and shows equations that give the diameters of the circles. We discuss the development of mathematical contents written by the scholar Yang Zhaoyun in Qing dynasty on the contents of 《Ceyuan Haijing》 in his book 《Jiuyong Yandai》. He derived equations to find the diameters of the circles based on algebraic knowledge known in the Qing dynasty. In this paper, we conclude that Yang's methods in devising the equations include the Gou-Gu Theorem, mathematical expressions derived from Gou-Gu ratio table, and the technique of interchanging triangles and events. We conclude that the Gou-Gu ratio table was a very important tool when Yang devised the equations in 《Ceyuan Haijing》.
\end{abstract}

Keywords: Gou-Gu Theorem, Ceyuan Haijing, Yang Zhaoyun, Jiuyong Yandai, Qing mathematics in the 19th century; 勾股整理, 測圓海鏡, 楊兆埩, 九容演代, 19世記 淸代數學.

MSC: 01A25

\section{Introduction}

The book 《Ceyuan Haijing (測圓海鏡)》 is completed in 1248 by Li Zhi (李治, 11921279) also known as Li Ye(李治) [4]. The mathematics in the book is to derive equations to find the diameter of the circle inscribed in a right triangle, and his basic tool for constructing equations is the Tianyuanshu. A circular fort with diameter set at 240 represented the circle. Different informations on the sections of the triangles are given in order to find the diameter of the circle through setting up algebraic equations. The problem is given two conditions: (i) $a^{2}+b^{2}=c^{2}$ and (ii) $D=a+b-c$ where $a, b, c$ mean the sides of the right triangle, and $D$ is the diameter of the inscribed circle. Li Zhi used one triangle as in $\langle$ Figure 1$\rangle$ to include all cases of inscribed and circumscribed circles. He converted the geometric problems to algebraic problems, where the given two events were lead to an equation on the circle. 
The mathematics of 《Ceyuan Haijing》was checked by Li Rui (李銳, 1768-1817) in 1798, and since then the book was well studied in Qing dynasty. For example, Li Shanlan (李善蘭, 1810-1882) completed 13 events with two triangles added in

《Ceyuan Haijing》 [2], Chen Weiqi (陳維祺, ca. end of 19c) worked on Gou-Gu ratio table and the principle of interchanging triangles and events [1], Yang Zhaoyun (楊 兆塉, ca. end of 19c) employed different techniques to construct equations for the diameters of the circles [7], Liu Yueyun (劉猋雲, ca. end of 19c) contributed to systematic comments on Li Zhi's work [5]. Yang, in fact, categorized the problems into 6 cases and worked with more than 600 problems, of which only 160 were recorded. ${ }^{1)}$

The following shows the form of questions in the book Ceyuan Haijing. ${ }^{2}$ )

[Suppose there is a circular fort of unknown diameter and circumference.]

One person walks out of the south gate 135 steps and another person walks out of the east gate 16 steps, and then they see each other.

[What is the diameter of the circular fort?]

Statements in the bracket above are the condition and the question tag of the problem. In $\langle$ Figure 2$\rangle$, the points $2,14,15$ and 3 respectively represent the west, south, east, north gates of the fort. ${ }^{3)}$

\subsection{Triangles and corresponding events and notations}

$\langle$ Figure 1> shows the circle inscribed in a right triangle and lines to the sides of the triangle are drawn. The triangles formed are labeled with a Chinese character at the right corner of the triangle. For example, the triangle labeled as great (大) is the largest triangle (with sides 320, 600, and 680). There are 15 triangles in Li Zhi's consideration, and the triangles are numbered at the vertices by Li Yan (李氅, 1892-1963) [3]. The sides are denoted by $a_{i}, b_{i}$ and $c_{i}$. Some triangles are congruent $\left(\Delta_{6} \equiv \Delta_{7}\right.$, $\Delta_{8} \equiv \Delta_{9}$ ). Sides of triangle $\Delta_{4}$ are twice those of $\Delta_{6}$, as $\Delta_{5}$ of $\Delta_{9}$. So, in the early discussion, only 11 different triangles were discussed.

\subsection{3 events of Gou-Gu (Triangle)}

The term $(c-b),(a+b-c)$ etc. are called events of a triangle. The 13 events included the events of the three side $(a),(b),(c)$, the five sums (五和),

$$
(a+b+c),(c+b),(c+a),(a+b),(c+b-a)
$$

1) A full list of problems treated by Yang in 6 cases is in Appendix 1.

2) The question is from question 2 of chapter 7 「卷七第二問。或問丙出南門。直行一百三十五步而立。甲出 東門。直行一十六步。見之。問答同前。」

3) In the old Chinese text, north is written below of south, and east is left of west, which is opposite with today's orientation. 


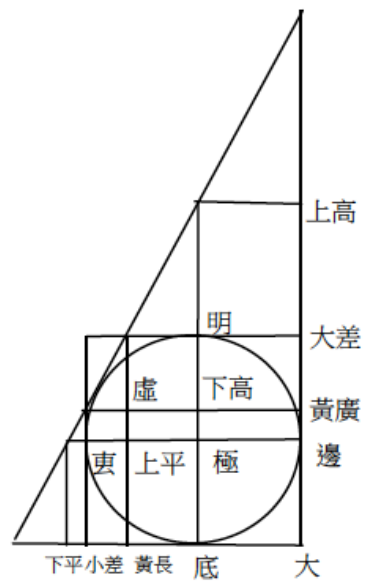

Fig. 1

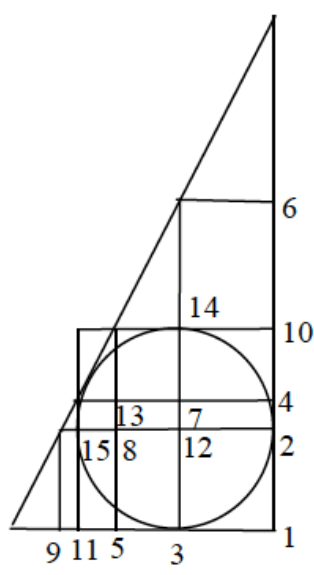

Fig. 2

Name of the triangle Denoted by numbers

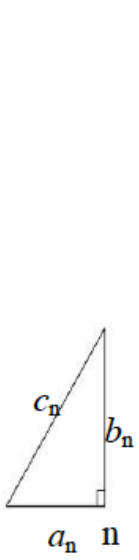

Fig. 3

Length

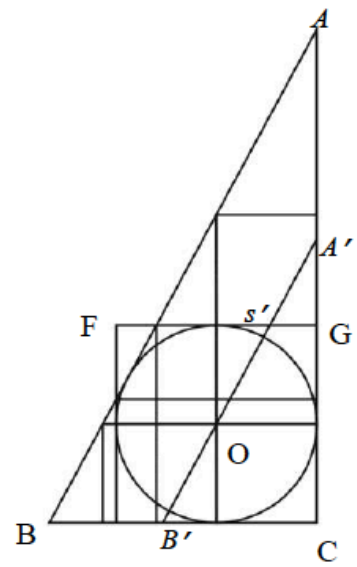

Fig. 4

Two triangles added

and the five differences (五較),

$$
(c-b+a),(a+b-c),(c-a),(c-b),(b-a) .
$$

The number of events " 13 " could be explained by the number of positive combinations of the three sides $(a, b$, and $c)$ of the triangle. The combinations of the lengths are $E_{i}=\alpha a+\beta b+\gamma c$ where each of $\alpha, \beta, \gamma$ take one of the values 1,0 , or -1 . Hence there are $3 \times 3 \times 3=27$ such cases. Now the case $(0,0,0)$ is deleted and we are left with 26 cases. As $E>0$, if we assume $c>b>a>0$ only above 13 of the 26 cases are positive. This is how the 13 events originated. All these 11 triangles are similar, and the perimeter of each $\Delta_{i}$ corresponds to an event of $\Delta_{1}$. For example, the perimeter of $\Delta_{2}$ is " $c+b$ " ( $c_{1}+b_{1}$, to be exact); so perimeter of $\Delta_{2}$ corresponds to the event $(c+b)$.

Each triangle has its 13 events and we denote the event $n$ of the triangle $m$ by $\Delta_{[m]}(n)$. For example, event $(a)$ of $\Delta_{[a+b+c]}\left(\right.$ or $\left.\Delta_{1}\right)$ is represented by $\Delta_{[a+b+c]}(a)$, which is equal to $a_{1}$. Note that no triangle in $\langle$ Figure 2$\rangle$ could correspond to a similar triangle with perimeter " $a+b$ " and " $b-a$ ", so there is no correspondence of the events $(a+b)$ and $(b-a)$ in Ceyuan Haijing. It is not until Li Shanlan, for the first time, added two more triangles and completed the system of 13 triangles and 13 events [2]. In $\langle$ Figure 4$\rangle$, the two new triangles $\Delta A^{\prime} B^{\prime} C$ and $\Delta A^{\prime} S^{\prime} G$ are formed by drawing a line $A^{\prime} B^{\prime}$ through $O$ parallel to $A B$ so that $A^{\prime} B^{\prime}$ intersects $F G$ at $S^{\prime}$. The perimeter of $\triangle A^{\prime} B^{\prime} C$ is " $a_{1}+b_{1}$ " and the perimeter of $\Delta A^{\prime} S^{\prime} G$ is " $b_{1}-a_{1}$ "; which corresponds to the events $(a+b)$ and $(b-a)$. Li Shanlan labeled $\triangle A^{\prime} B^{\prime} C$ as "Combine triangle" (合, denoted by $\Delta_{16}$ or $\Delta_{[a+b]}$ ) and $\Delta A^{\prime} S^{\prime} G$ as "Divide triangle" (斷, denoted by $\Delta_{17}$ or 


\begin{tabular}{|c|c|c|c|c|c|c|c|c|c|c|c|c|}
\hline$\Delta_{1}$ & $\Delta_{2}$ & $\Delta_{3}$ & $\Delta_{6}$ & $\Delta_{9}$ & $\Delta_{10}$ & $\Delta_{11}$ & $\Delta_{12}$ & $\Delta_{13}$ & $\Delta_{14}$ & $\Delta_{15}$ & $\Delta_{16}$ & $\Delta_{17}$ \\
\hline 大 & 邊 & 底 & 高 & 平 & 大差 & 小差 & 極 & 虛 & 明 & 叀 & 合 & 斷 \\
\hline$[\mathrm{a}+\mathrm{b}+\mathrm{c}]$ & {$[\mathrm{c}+\mathrm{b}]$} & {$[\mathrm{c}+\mathrm{a}]$} & {$[\mathrm{b}]$} & {$[\mathrm{a}]$} & {$[\mathrm{c}+\mathrm{b}-\mathrm{a}]$} & {$[\mathrm{c}-\mathrm{b}+\mathrm{a}]$} & {$[\mathrm{c}]$} & {$[\mathrm{a}+\mathrm{b}-\mathrm{c}]$} & {$[\mathrm{c}-\mathrm{a}]$} & {$[\mathrm{c}-\mathrm{b}]$} & {$[\mathrm{a}+\mathrm{b}]$} & {$[\mathrm{b}-\mathrm{a}]$} \\
\hline 和和 & 大和 & 小和 & 股 & 勾 & 較和 & 較較 & 弦 & 和較 & 大較 & 小較 & 和 & 較 \\
\hline
\end{tabular}

Table 1 . The 13 triangles and the 13 events.

\begin{tabular}{|c|c|c|c|c|c|c|c|c|c|c|c|}
\hline & & & & & & b-a & $\mathbf{a}+\mathbf{b}$ & c & b & $\mathbf{a}$ & \\
\hline 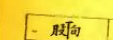 & 甸牦 & 锌 & If & & 率 & $(c+b+a)(b-a)$ & $(\mathrm{c}+\mathrm{b}+\mathrm{a})(\mathrm{a}+\mathrm{b})$ & $(c+b+a) c$ & $(c+b+a) b$ & $(c+b+a) a$ & 通率 \\
\hline 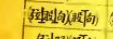 & 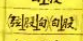 & 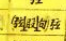 & 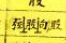 & 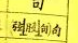 & 整通慗 & $(\mathrm{c}+\mathrm{b})(\mathrm{b}-\mathrm{a})$ & $(\mathrm{c}+\mathrm{b})(\mathrm{a}+\mathrm{b})$ & $(\mathrm{c}+\mathrm{b}) \mathrm{c}$ & $(\mathrm{c}+\mathrm{b}) \mathrm{b}$ & $(\mathrm{c}+\mathrm{b}) \mathrm{a}$ & 邊率 \\
\hline 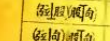 & 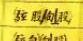 & Salyek & (4) & 列双句 & 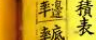 & $(c+a)(b-a)$ & $(c+a)(a+b)$ & $(c+a) c$ & $(\mathrm{c}+\mathrm{a}) \mathrm{b}$ & $(c+a) a$ & 底率 \\
\hline 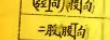 & 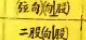 & 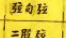 & 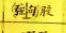 & 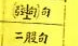 & 廣黄 & & & & & & 代率 \\
\hline 二旬保响 & 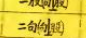 & 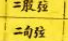 & 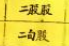 & $\begin{array}{l}\text { 二股向 } \\
\text { 二的 }\end{array}$ & 長黄 & $2 b(b-a)$ & $2 \mathrm{~b}(\mathrm{a}+\mathrm{b})$ & $2 \mathrm{bc}$ & $2 \mathrm{bb}$ & $2 \mathrm{ba}$ & 黃廣 \\
\hline 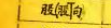 & 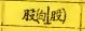 & 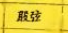 & 䏠能 & 股向 & 車高 & $2 a(b-a)$ & $2 \mathrm{a}(\mathrm{a}+\mathrm{b})$ & $2 \mathrm{ac}$ & $2 \mathrm{ab}$ & 2aa & 革長 \\
\hline 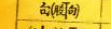 & 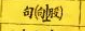 & 句㱞 & 蜼 & 的 & 率平 & & & & & & \\
\hline 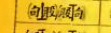 & 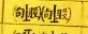 & 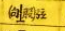 & 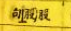 & (bllर出 & 辁 & b(b-a) & $b(a+b)$ & $\mathrm{bc}$ & $\mathrm{bb}$ & ba & 高率 \\
\hline 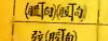 & 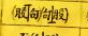 & 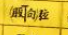 & 次何设 & 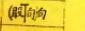 & 米噛 & $a(b-a)$ & $a(a+b)$ & ac & $a b$ & aa & 平永 \\
\hline 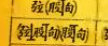 & 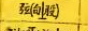 & 柆㕸 & 张俶 & 弦向 & 棵量 & & & & & & \\
\hline 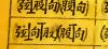 & 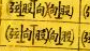 & 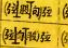 & 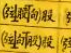 & 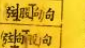 & 美大 & $(a+b)(b-a)$ & $(a+b)(a+b)$ & $(a+b) c$ & $(a+b) b$ & $(a+b) a$ & 合率 \\
\hline 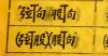 & 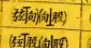 & (5) & 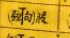 & 㢸甸向 & 率明 & $(b-a)(b-a)$ & $(b-a)(a+b)$ & $(\mathrm{b}-\mathrm{a}) \mathrm{c}$ & (b-a)b & (b-a)a & 断率 \\
\hline 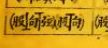 & 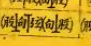 & 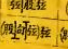 & 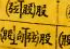 & 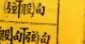 & 率虫 & $c(b-a)$ & $c(a+b)$ & $\mathrm{cc}$ & $\mathrm{cb}$ & $\mathrm{ca}$ & 皇極 \\
\hline & & & & & & $(c+b-a)(b-a)$ & $(\mathrm{c}+\mathrm{b}-\mathrm{a})(\mathrm{a}+\mathrm{b})$ & $(c+b-a) c$ & $(\mathrm{c}+\mathrm{b}-\mathrm{a}) \mathrm{b}$ & $(\mathrm{c}+\mathrm{b}-\mathrm{a}) \mathrm{a}$ & 大差 \\
\hline \multirow{4}{*}{\multicolumn{6}{|c|}{$\begin{array}{l}\text { Above is part of the table of Chen, } \\
\text { the translation is on the right. }\end{array}$}} & $(c+a-b)(b-a)$ & $(c+a-b)(a+b)$ & $(\mathrm{c}+\mathrm{a}-\mathrm{b}) \mathrm{c}$ & $(\mathrm{c}+\mathrm{a}-\mathrm{b}) \mathrm{b}$ & $(\mathrm{c}+\mathrm{a}-\mathrm{b}) \mathrm{a}$ & 小差 \\
\hline & & & & & & $(c-a)(b-a)$ & $(c-a)(a+b)$ & $(\mathrm{c}-\mathrm{a}) \mathrm{c}$ & $(\mathrm{c}-\mathrm{a}) \mathrm{b}$ & $(c-a) a$ & 明率 \\
\hline & & & & & & (c-b) (b-a) & $(\mathrm{c}-\mathrm{b})(\mathrm{a}+\mathrm{b})$ & $(\mathrm{c}-\mathrm{b}) \mathrm{c}$ & $(\mathrm{c}-\mathrm{b}) \mathrm{b}$ & (c-b)a & 惠率 \\
\hline & & & & & & $(b+a-c)(b-a)$ & $(b+a-c)(a+b)$ & $(b+a-c) c$ & $(b+a-c) b$ & $(b+a-c) a$ & 太虛 \\
\hline
\end{tabular}

Table 2. The table of Chen and its translation.

$\left.\Delta_{[b-a]}\right)$. The Table 1 summarizes the information of the 13 triangles and the 13 events correspondingly. (See [2] and Chap. 1 of [4].)

\subsection{Interchange of triangles and events}

Based on the notation $\Delta_{[m]}(n)$, we can easily express the principle of "interchanging of triangles and events", that is, $\Delta_{[m]}(n)=\Delta_{[n]}(m)$. For example ${ }^{4)}$, in the shaded boxes of the following table of Chen, $(a+b)$ of (斷率) is represented by $(b-a)(a+b)$, and the representation of $(b-a)$ in $\Delta_{16}$ (合率) is $(a+b)(b-a)$. Both expressions are equal $\left(\Delta_{[b-a]}(a+b)=\Delta_{[a+b]}(b-a)\right)$. This principle could be easily verified by ratio as follows (See Table 2):

$$
\Delta_{[b-a]}(a+b)=\left(\frac{b-a}{a+b+c}\right) \times(a+b)=\left(\frac{a+b}{a+b+c}\right) \times(b-a)=\Delta_{[a+b]}(b-a) .
$$

Qian Baocong (錢寶琮, 1892-1974) concluded that the principle brought by Chen could be used to work out the validity of the mathematical expressions in Shibie Zaji

4) Though the notation $\Delta_{[a]}(c+b)=\Delta_{[c+b]}(a)$ correctly describe the relation, the shortened form of representation is accordingly simpler. The paper will use the shortened form of representation when needed, for example, writing instead of $\Delta_{[c+b]}(b) \Delta_{[a+b+c]}(c)=\Delta_{[a+b+c]}(b) \Delta_{[c+b]}(c)$, etc. 
(識別雜記) of Ceyuan Haijing [6]. Yang used the technique to devise the equations, though he did not explicitly wrote it down as a principle. The principle could also be applied to two triangles. Since all triangles $\Delta_{[m]}$ and $\Delta_{[n]}$ are similar, we have

$$
\frac{\Delta_{[m]}(p)}{\Delta_{[n]}(p)}=\frac{\Delta_{[m]}(q)}{\Delta_{[n]}(q)} \quad \text { or } \quad \Delta_{[m]}(p) \Delta_{[n]}(q)=\Delta_{[m]}(q) \Delta_{n}(p),
$$

that is, the product of two events of two triangles could also be interchanged. For example, $\Delta_{[c+b]}(b) \Delta_{[a+b+c]}(c)=\Delta_{[a+b+c]}(b) \Delta_{[c+b]}(c)$, or $b_{2} \cdot c_{1}=b_{1} \cdot c_{2}$ which means $\{$ [邊股] [大弦] $=$ [大股] [邊弦] $\}$; this represents the equality of the ratios of two sides of two triangles $\Delta_{2}$ and $\Delta_{1}$.

\section{Yang's work in Ceyuan Haijing}

\subsection{The Gou-Gu ratio table and its formation}

Solving the problems in Ceyuan Haijing, mathematicians in the Qing Dynasty used a table of Gou-Gu ratio (勾股比例). The ratio table is an important tool in working with Ceyuan Haijing, yet it did not attract enough attention it deserved. In fact, many scholars in the Qing Dynasty set up their own ratio table. The Table 3 is a table set up by Liu Yueyun, and the Table 4 is set up by Yang Zhayun. The Gou-Gu table formed is based on the Pythagorean Theorem. As $c^{2}=a^{2}+b^{2}$ and so $\frac{(c+b)}{a}=\frac{a}{(c-b)}$. This formed the 4 upper left grids of the table $(Y)$, and by

$$
\frac{(c+b)}{a}=\frac{a}{(c-b)}=\frac{(c+b)-a}{a-(c-b)}=\frac{(c+b)+a}{a+(c-b)}
$$

the first two rows of the table are formed. We then subtract R2 from R1 to make Row 3, and adding R1 with R2 to make Row 4. This completes the table as in Table 5.

There are 36 cases of cross-multiplications from the 16 grids tables, but only 21 of them are distinct. ${ }^{5)}$ As the two terms $(b-a)$ and $(b+a)$ are not factors of the Pythagorean theorem, they are not in the table. Each element in the tables corresponds to an event of a triangle, for example $(c+b)$ corresponds to event 2 . All of the 13 events except $(c),(b+a)$ and $(b-a)$ are in the table.

Apart from the 10 different events appearing in the table, the 21 cross multiplications provide a mathematical relationship of the sides of a triangle. For example, we get $a \times(a+b-c)=(c-b) \times(c+b-a)$ by \begin{tabular}{c|c|c|}
\hline$a$ & $c+b-a$ \\
\hline$c-b$ & $a+b-c$ \\
\hline
\end{tabular}

The cross multiplications also give the relations of pairs of events of two triangles. The expression $a \times(a+b-c)=(c-b) \times(c+b-a)$ is equivalent to

$$
\frac{a}{(a+b+c)} \times(a+b-c)=\frac{c+b-a}{(a+b+c)} \times(c-b),
$$

5) The list of all the expressions is in Appendix 2. 


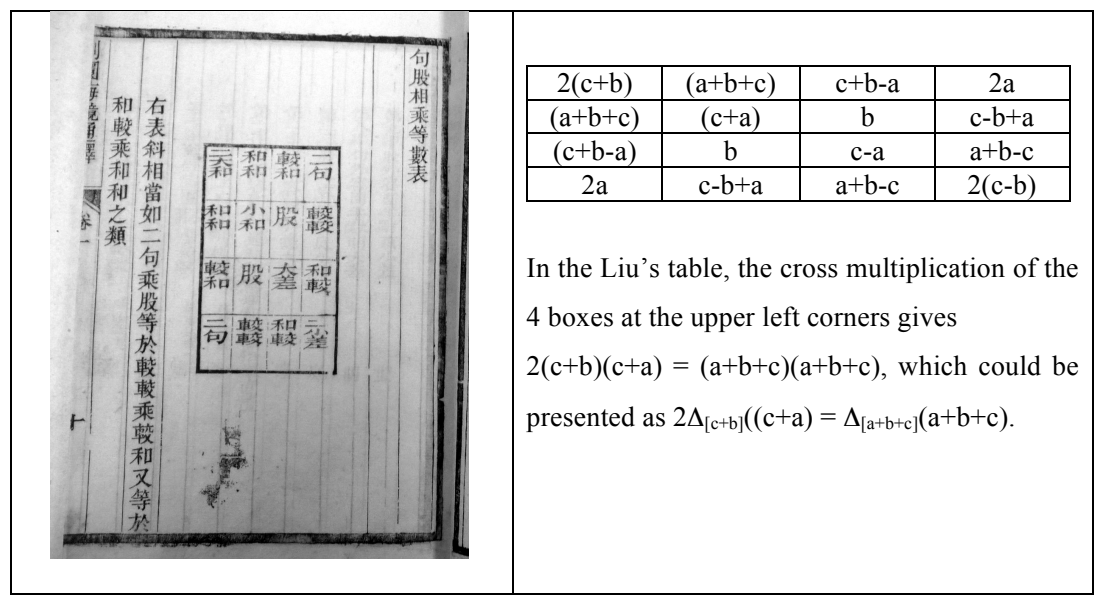

Table 3. The ratio table of Liu Yueyun.

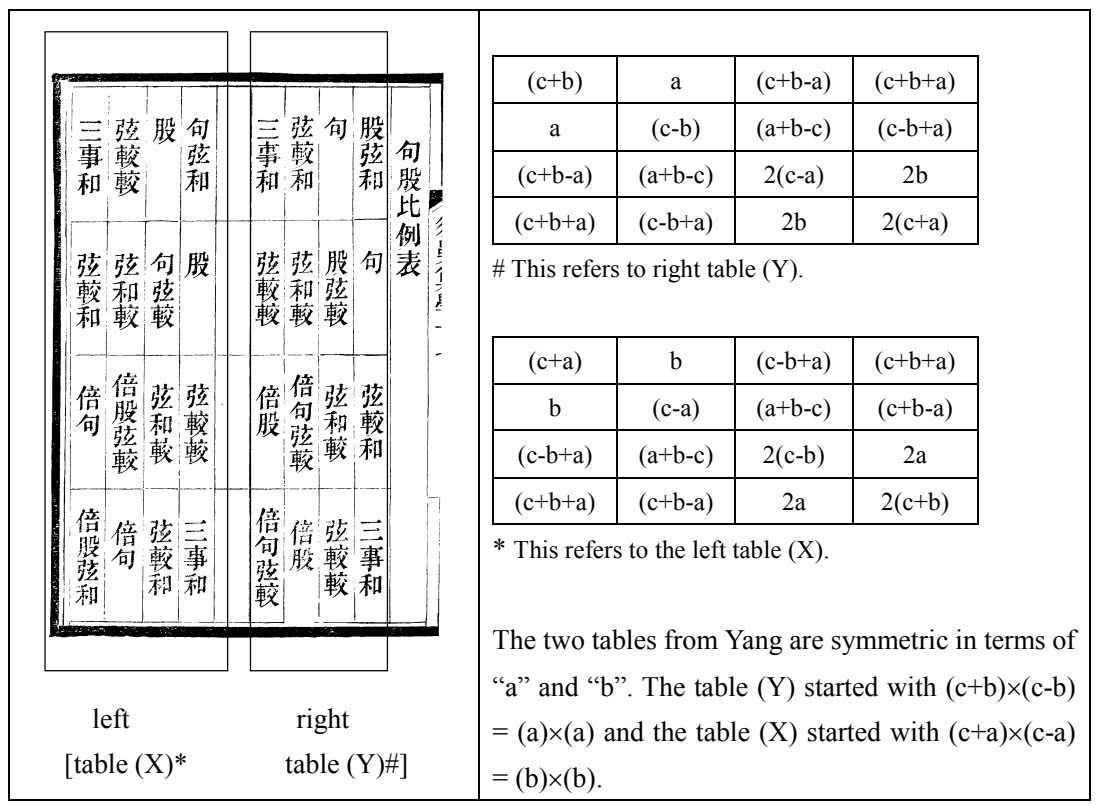

Table 4. Two ratio table by Yang.

\begin{tabular}{c|c|c|c|c|}
\multicolumn{1}{c}{} & \multicolumn{1}{c}{ C1 } & C2 & C1-C2 & $\mathbf{C 1}+\mathbf{C} 2$ \\
\cline { 2 - 5 } $\mathbf{R} 1$ & $\mathrm{c}+\mathrm{b}$ & $\mathrm{a}$ & $\mathrm{c}+\mathrm{b}-\mathrm{a}$ & $\mathrm{c}+\mathrm{b}+\mathrm{a}$ \\
\cline { 2 - 5 } $\mathbf{R 2}$ & $\mathrm{a}$ & $\mathrm{c}-\mathrm{b}$ & $\mathrm{a}+\mathrm{b}-\mathrm{c}$ & $\mathrm{c}-\mathrm{b}+\mathrm{a}$ \\
\hline $\mathbf{R} 1-\mathbf{R} 2$ & $\mathrm{c}+\mathrm{b}-\mathrm{a}$ & $\mathrm{a}+\mathrm{b}-\mathrm{c}$ & $2(\mathrm{c}-\mathrm{a})$ & $2 \mathrm{~b}$ \\
\hline $\mathbf{R} 1+\mathbf{R} 2$ & $\mathrm{c}+\mathrm{b}+\mathrm{a}$ & $\mathrm{c}-\mathrm{b}+\mathrm{a}$ & $2 \mathrm{~b}$ & $2(\mathrm{c}+\mathrm{a})$ \\
\cline { 2 - 5 } & & & &
\end{tabular}

Table 5. The construction of the table (Y). 
and could be represented as $\Delta_{[a]}(a+b-c)=\Delta_{[c+b-a]}(c-b)$, or $(a+b-c)_{9}=(c-b)_{10}$.

\subsection{Construction of mathematical formulae from Gou-Gu table}

In Yang's work, he provided formula that could be used with Pythagorean theorem and its variations, or relations that come from interchanging triangles and events. Yang did not explain how he got these expressions, yet we could trace them to the Gou-Gu ratio table. We give a few examples here.

Example 1 (Question 9 on $a_{1}$ ).

Formula: (i) $\frac{\text { 二句 }}{\text { 天二 }^{\text {二 }}}$ 高弦和較 ${ }^{6)}$ and (ii) $\frac{\text { 二大句 }{ }^{\mathrm{T} \text { 二天 }}}{\text { 天 }^{二}}=$ 大句弦較

In question 9 of $a_{1}$, Yang made use of two formulae.

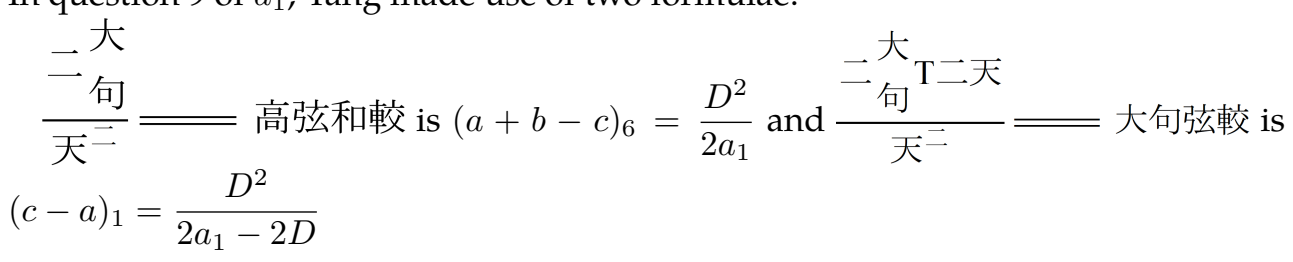

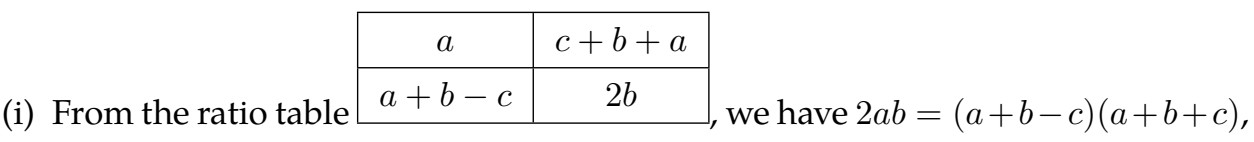
and so

$$
\frac{b}{(a+b+c)}(a+b-c)=\frac{(a+b-c)^{2}}{2 a}
$$

and hence the formula $(a+b-c)_{6}=\frac{D^{2}}{2 a_{1}}$.

(ii) From the ratio table \begin{tabular}{|c|c|}
\hline$c-b$ & $a+b-c$ \\
\hline$a+b-c$ & $2(c-a)$ \\
\hline
\end{tabular} , we have $2(c-a)(c-b)=D^{2}$ and so $(c-a)=\frac{D^{2}}{2(c-b)} ;$ which in turn gives $(c-a)_{1}=\frac{D^{2}}{2 a_{1}-2 D}$.

Example 2 (Question 3 on $a_{9}$ )

Formula: 明句弦和 $=$ 高股.

And in question 3 of $a_{9}$ ，(明句弦和 $=$ 高股 $)$ is $(c+a)_{14}=b_{6}$.

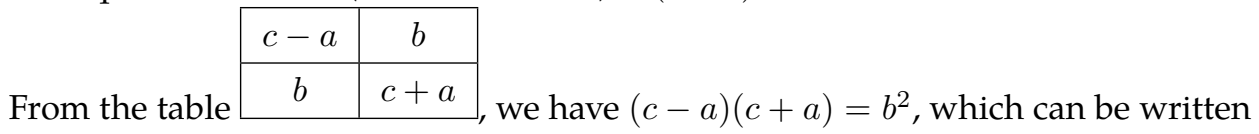
as

$$
\frac{c-a}{a+b+c}(c+a)=\frac{b}{a+b+c} b \quad \text { or } \quad(c+a)_{14}=b_{6} .
$$

6) The representation of fractions in the Qing dynasty is different from today, the element below the fraction line is the numerator, and the element above the line is the denominator. 
Example 3 (Question 16 on $c_{1}$ )

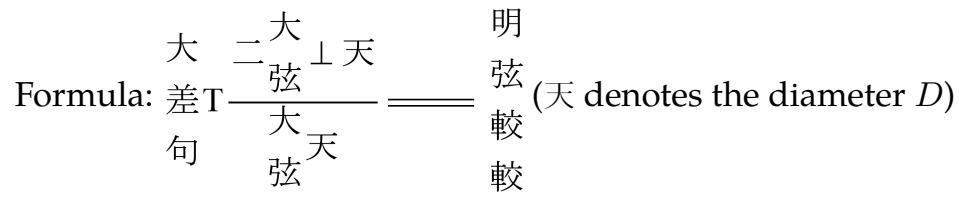

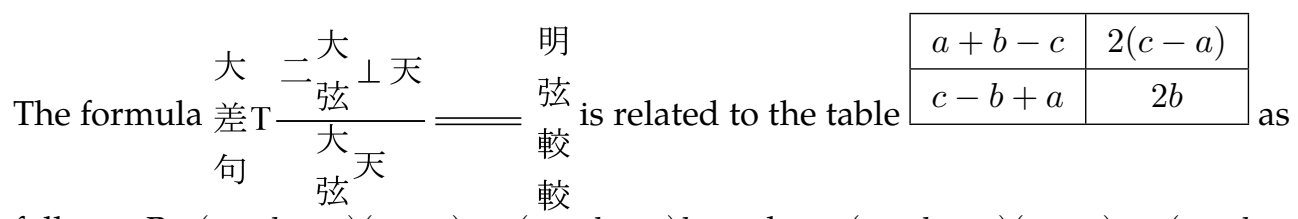
follows: By $(c-b+a)(c-a)=(a+b+c) b$, we have $(c-b+a)(c-a)=(c+b-$ $a) a-c(a+b-c)$ and so

$$
\frac{c-a}{a+b+c}(c-b+a)=\frac{c+b-a}{a+b+c}(a)-\frac{a+b-c}{a+b+c}(c) .
$$

Hence $\frac{c-a}{a+b+c}(c-b+a)=\frac{c+b-a}{a+b+c}(a)-\frac{D}{2 c+D}(c)$, which is $\underset{\text { 較 }}{\text { 較 }}=\underset{\text { 句 }}{=} \frac{\text { 二弦 }}{\text { 大 天 }}$ 天

\subsection{The work of Yang}

In Jiuyong Yandai (九容演代, 1898), Yang used algebraic method to solve all the problems in Ceyuan Haijing systemically. His work involved constructing equations on 6 cases of questions, including questions on $a_{1}$ (34 questions), $b_{1}$ (33 questions), $c_{1}$ (32 questions), $a_{9}$ (20 questions), $c_{9}$ (20 questions) and $a_{15}$ (21 questions).

We summarize the techniques used by Yang as follows.

\subsection{Technique 1: Using Gou-Gu Theorem (Pythagorean Theorem)}

One of the techniques used by Yang is the Pythagorean Theorem. Yang obtained the three sides of the triangle and used the theorem to obtain the equation. We illustrate his work with a few examples and then listed all the cases he employed in his work. ${ }^{7}$ )

\section{Example 1 (Question 32 on $a_{1}$ )}

Find the diameter, given the lengths of $a_{1}$ and $a_{16}$.

Yang expressed the three sides of the triangle $\Delta_{9}$ into expressions related to $\Delta_{16}$. He got " $b_{9}=r$ ", " $a_{9}=\left(a_{16}-r\right)$ and $c_{9}=\left(a_{1}-a_{16}\right)$." Then the theorem $b_{9}{ }^{2}+a_{9}{ }^{2}=c_{9}{ }^{2}$ is used, and obtained the equation $r^{2}+\left(a_{16}-r\right)^{2}=\left(a_{1}-a_{16}\right)^{2}$. 


\section{Example 2 (Question 8 on $b_{1}$ )}

Find the diameter, given the lengths of $b_{1}$ and $b_{14}$.

With $r=a_{6}, c_{6}=b_{14}+r, b_{6}=b_{1}-b_{14}-2 r$ and $a_{6}{ }^{2}+b_{6}{ }^{2}=c_{6}{ }^{2}$, equation $r^{2}+\left(b_{1}-b_{14}-\right.$ $2 r)^{2}=\left(b_{14}+r\right)^{2}$ is obtained and in turn we have $-b_{1}^{2}+2 b_{1} b_{14}+\left(4 b_{1}-2\right) r-4 r^{2}=0$

\section{Example 3 (Question 4 on $a_{9}$ )}

Find the diameter, given the lengths of $a_{9}$ and $b_{14}$.

With $r=a_{6}, b_{6}=\frac{r^{2}}{a_{9}}, c_{6}=b_{14}+r$, and the relation $a_{6}{ }^{2}+b_{6}{ }^{2}=c_{6}{ }^{2}$, one has $r^{2}+\frac{r^{4}}{a_{9}{ }^{2}}=$ $\left(b_{14}+r\right)^{2}$, and hence the equation $a_{9}^{2} b_{14}^{2}+2 a_{9}^{2} b_{14}-r^{4}=0$.

\section{Example 4 (Question 9 on $c_{9}$ )}

Find the diameter, given the lengths of $c_{9}$ and $c_{2}$.

By using $r=b_{9}, c_{9}+r=a_{2}, a_{9}=\frac{c_{9}{ }^{2}+c_{9} r}{c^{2}}$, and $c_{9}{ }^{2}=a_{9}{ }^{2}+b_{9}{ }^{2}$, substitution gives $c_{9}{ }^{2}=\frac{c_{9}{ }^{4}+2 c_{9}{ }^{3} r+c_{9}{ }^{2} r^{2}}{c_{2}{ }^{2}}+r^{2}$ and hence the equation $\left(c_{2}{ }^{2}+c_{9}{ }^{2}\right) r^{2}+2 c_{9}{ }^{3} r-c_{2}{ }^{2} c_{9}{ }^{2}+$ $c_{9}{ }^{4}=0$.

\subsection{Technique 2: Using the Gou-Gu ratio table}

Apart from constructing mathematical formulae from the ratio table, Yang also used the 21 relations from the Gou-Gu ratio table to devise mathematical expressions that he could use for individual questions. These 21 relations are the variation of the Pythagorean Theorem, such as $(c-a)(c+a)=b^{2}, 2 a b=(c+b+a)(a+b-c)$ etc. Yang applied the relation to one triangle or two triangles to obtain his equations.

We provide a few examples here.

\section{Example 1 (Question 6 on $c_{9}$ )}

Find the diameter, given the lengths of $c_{9}$ and $a_{13}$.

Yang applied the relation $2(c-a)(c+a)=(a+b-c)^{2}$ to $\Delta_{9}$ and obtained $2(c-a)_{9}(c-b)_{9}=$ $(a+b-c)_{9}^{2}$. By

$$
a_{13}=(a+b-c)_{9}, \quad(c-a)_{9}=r-a_{13}, \quad(c-b)_{9}=c_{9}-r
$$

one has $2\left(c_{9}-r\right)\left(r-a_{13}\right)=a_{13}{ }^{2}$, and the equation

$$
-2 r^{2}+\left(2 c_{9}+2 a_{13}\right) r-2 a_{13} c_{9}-a_{13}^{2}=0 .
$$

Example 2 (Question 3 on $a_{9}$ )

Find the diameter, given the lengths of $a_{9}$ and $c_{15}$. 
The relation $(a+b-c)(a+c)=b(c-b+a)$ is applied to the two triangles $\Delta_{11}$ and $\Delta_{14}$, that is,

$$
\begin{aligned}
& (a+b-c)_{11}(a+c)_{11}=b_{11}(c-b+a)_{11} \quad \text { and } \\
& (a+b-c)_{14}(a+c)_{14}=b_{14}(c-b+a)_{14} .
\end{aligned}
$$

By ratio consideration one has

$$
\frac{(a+b-c)_{11}}{b_{11}}=\frac{(c-b+a)_{11}}{(a+c)_{11}}=\frac{(c-b+a)_{14}}{(a+c)_{14}}
$$

and therefore $\{[$ 小差弦和較 $]$ [明句弦和 $]=[$ 小差股 $]$ [明弦較較 $]\}$. Substitution gives

$$
\begin{array}{ll}
(a+b-c)_{11}=r \cdot a_{9}-2 c_{15}, & (c+a)_{14}=b_{6}=\frac{r^{2}}{a_{9}}, \\
(c-b+a)_{14}=\left(r-a_{9}+c_{15}\right), & b_{11}=\left(r+a_{9}-c_{15}\right),
\end{array}
$$

and equation $\left(2 c_{15}-a_{9}\right) r^{2}-a_{9}{ }^{3}+2 a_{9}{ }^{2} c_{15}-a_{9} c_{15}{ }^{2}=0$ is obtained.

\section{Example 3 (Question 4 on $b_{1}$ )}

Find the diameter, given the lengths of $b_{1}$ and $a_{15}$.

In this question, the relation $(c-b)(c+b)=a^{2}$ is applied to two triangles, $\Delta_{1}$ and $\Delta_{15}$, and the relation is $(c-b)_{1} \cdot(c+b)_{15}=a_{1} \cdot a_{15}$ or $\{[$ 大股弦較] [叀股弦和 $]=$ [大句] [叀句]\}. By

$$
\begin{aligned}
& (c-b)_{1}=\frac{D^{2}}{2 b_{1}-2 D}, \quad(c+b)_{15}=\frac{D^{2}}{2 b_{1}-2 D}-a_{15}, \\
& a_{1}=\frac{D^{2}}{2 b_{1}-2 D}+D,
\end{aligned}
$$

and subsequent substitution, Yang has the equation

$$
\left(\frac{D^{2}}{2 b_{1}-2 D}\right)\left(\frac{D^{2}}{2 b_{1}-2 D}-a_{15}\right)=\left(\frac{D^{2}}{2 b_{1}-2 D}+D\right) \cdot a_{15}
$$

which is $-D^{3}-4 b_{1} a_{15} D+4 b_{1}^{2} a_{15}=0$.

\section{Example 4 (Question 10 on $a_{15}$ )}

Find the diameter, given the lengths of $a_{15}$ and $c_{10}$.

The relation $b \cdot 2 a=(c-b+a)(c+b-a)$ is applied to the two triangles $\Delta_{9}$ and $\Delta_{12}$, that is, $b_{9} \cdot 2 a_{12}=(c-b+a)_{9} \cdot(c+b-a)_{12}$, or $\{[$ 平股] [倍太極句] $=$ [平弦較較] [太極弦較和] $\}$. By

$$
\begin{aligned}
& c_{10}=(c+b-a)_{12}, \quad\left(a_{15}+r\right)=a_{12}, \\
& \frac{\left(2 r+a_{15}\right)\left(a_{15}+r\right)}{r+a_{15}+c_{10}}+a_{15}=(c-b+a)_{9}
\end{aligned}
$$

and using substitution, Yang gets

$$
r \cdot 2\left(a_{15}+r\right)=\left[\frac{\left(2 r+a_{15}\right)\left(a_{15}+r\right)}{r+a_{15}+c_{10}}+a_{15}\right] \cdot c_{10},
$$

and then the equation $-2 r^{3}-4 a_{15} r^{2}+\left(2 a_{15} c_{10}-2 a_{15}{ }^{2}\right) r+\left(2 a_{15}{ }^{2} c_{10}+a_{15} c_{10}^{2}\right)=0$. 


\subsection{Technique 3: Using the principle of Interchange of triangles and events}

Interchanging event and triangle is a technique which was used quite frequently in Yang's work. ${ }^{8)}$ We illustrate his process with the following examples.

Example 1 (Question 9 on $a_{1}$ )

Find the diameter, given the length of $a_{1}$ and $b_{14}$.

The principle of interchanging involved $(a+b-c)_{6}(c-a)_{1}=(a+b-c)_{1}(c-a)_{6}$ ， $\{[$ 高弦和較 $][$ 大句弦較 $]=[$ 大弦和較 $][$ 高句弦較 $]\}$. By

$$
\begin{aligned}
& (a+b-c)_{1}=D, \quad(c-a)_{6}=b_{4}, \\
& (a+b-c)_{6}=\frac{D^{2}}{2 a_{1}},(c-a)_{1}=\frac{D^{2}}{2 a_{1}-2 D},
\end{aligned}
$$

and substituting, Yang got $\left(\frac{D^{2}}{2 a_{1}} \frac{D^{2}}{2 a_{1}-2 D}\right)=D \cdot b_{14}$ and hence $-D^{3}-4 a_{1} b_{14} D+$ $4 a_{1}^{2} b_{14}=0$.

\section{Example 2 (Question 14 on $c_{1}$ )}

Find the diameter, given the length of $c_{1}$ and $b_{2}$.

The interchanging involved the relation $b_{9} \cdot(a+c)_{2}=b_{2} \cdot(a+c)_{9},\{[$ 平股] [邊句弦和 $]=$ [邊股] [平句弦和] $\}$. By $b_{9}=r,(a+c)_{2}=\left(c_{1}+r\right),(a+c)_{9}=\left(c_{1}-b_{2}\right)$ and subsequent substitution gives $r\left(c_{1}+r\right)=b_{2}\left(c_{1}-b_{2}\right)$, and the equation $-r^{2}-c_{1} r+\left(b_{2} c_{1}-b_{2}^{2}\right)=0$.

Example 3 (Question 11 on $a_{15}$ )

Find the diameter, given the length of $a_{15}$ and $b_{11}$.

The relation of interchanging here is $b_{9} \cdot c_{15}=b_{15} \cdot c_{9},\{[$ 平股] [叀弦] $=$ [叀股] [平弦] $\}$ ， with $b_{9}=r, b_{15}=b_{11}-b_{9}, c_{9}=a_{15}+b_{9}, c_{15}=\frac{b_{11} \cdot a_{15}}{b_{11}-b_{9}}-a_{15}-b_{11}+b_{9}$, substitution gives

$$
r \cdot\left(\frac{b_{11} \cdot a_{15}}{b_{11}-b_{9}}-a_{15}-b_{11}+b_{9}\right)=\left(b_{11}-b_{9}\right) \cdot\left(a_{15}+b_{9}\right),
$$

and $2 r^{3}-4 b_{11} r^{2}+\left(2 b_{11}^{2}-2 b_{11} a_{15}\right) r+b_{11}^{2} a_{15}=0$.

\section{Example 4 (Question 11 on $c_{9}$ )}

Find the diameter, given the length of $c_{9}$ and $b_{10}$.

The interchanging relation is $(c-b)_{9} \cdot b_{1}=(c-b)_{1} \cdot b_{9}$, or $\{[$ 平股弦較] [大股] $=$ [大股弦較] [平股] $\}$, with $b_{9}=r,(c-b)_{9}=c_{9}-r, b_{1}=b_{10}-2 r,(c-b)_{1}=\frac{2 r^{2}}{b_{10}}$, substitution gives $\left(c_{9}-r\right)\left(b_{10}-2 r\right)=\frac{2 r^{2}}{b_{10}} \cdot r$, and $2 r^{3}+2 b_{10} r^{2}+\left(b_{10}^{2}-2 b_{10} c_{9}\right) r-$ $b_{10}^{2} c_{9}=0$.

8) A full list of questions of Yang using this technique (with interchanging relation) is in Appendix 4. 


\subsection{Other approaches used by Yang}

Apart from the above techniques, Yang also employed different relations to solve the questions. For example, the relation $a_{15} \cdot a_{2}=a_{9}^{2}$ is used by Yang to devise equations with conditions $\left(a_{1}, a_{15}\right)$, and $\left(a_{1}, a_{17}\right)$ (question 5 and 29 for case $\left.a_{1}\right)$; and also for the condition $\left(a_{15}, c_{3}\right)$ and $\left(a_{15}, a_{16}\right)$ (question 14 and 19 for the case $\left.a_{15}\right)$. The relation $2 a_{2} \cdot a_{3}=a_{1}^{2}$ is used in question 26 of $a_{1}$, with condition $\left(a_{1}, a_{12}\right)$.

There is one question treated by Yang which involves a different expression of the same mathematical term $(c-b)_{10}$ with conditions $\left(a_{15}, b_{10}\right)$ (question 9 on $\left.a_{15}\right)$.

Example 1 (Question 9 on $a_{15}$ )

Find the diameter, given the length of $a_{15}$ and $b_{10}$.

Yang obtained two different expressions for $(c-b)_{10}$. By $(c-b)_{10}=\frac{2 r^{2}}{2 r+b_{10}}$ and $(c-b)_{10}=\frac{a_{15} \cdot b_{10}}{r}$, which implies $\frac{2 r^{2}}{2 r+b_{10}}=\frac{a_{15} \cdot b_{10}}{r}$, and the equation $2 r^{3}=$ $\left(2 r+b_{10}\right)\left(a_{15} \cdot b_{10}\right)$ is obtained.

One mathematical relation used by Yang and not in the Gou-Gu table, is the expression $(b-a)^{2}+(a+b)^{2}=2 c^{2}$, which is in Question 10 of the case $c_{9}$. We include the process here.

\section{Example 2 (Question 10 on $c_{9}$ )}

Find the diameter, given the length of $c_{9}$ and $a_{10}$.

In this question, the relation $(b-a)^{2}+(a+b)^{2}=2 c^{2}$ is employed to $\Delta_{9}$, and so $(b-a)_{9}{ }^{2}+(a+b)_{9}{ }^{2}=2 c_{9}{ }^{2}$, with $(b-a)_{9}=\left(a_{10}-c_{9}\right)$ and $(a+b)_{9}=\left(c_{9}+2 r-a_{10}\right)$, the relation becomes $\left(a_{10}-c_{9}\right)^{2}+\left(c_{9}+2 r-a_{10}\right)^{2}=2 c_{9}{ }^{2}$

\section{Conclusion}

Yang's work is important as he gave a systematic work on nearly all the problems in $\langle$ Ceyuan Haijing $》$. His approaches are completely algebraic. He considered two events of given triangles and transformed the events into expressions involving one or two triangles. This could be done through either direct applications of Pythagorean Theorem, the relations from the Gou-Gu ratio table or interchanges of triangles and events. Yang also worked out some standard formulae of certain events (some of which are from the results of cross multiplication of the Gou-Gu ratio table), so that he could use them to substitute and get a new mathematical expressions. Through the interchanges of triangles and events or using the formulae, the subsequent substitution resulted in equations which are subject to the conditions of two events of any two triangles. 


\section{References}

1. Chen Weiqi, Zhong Xi Suan Xue Da Cheng 41, 1889. 陳維祺, 中西算學大成 41 卷, 1889.

2. Li Shanlan, Jiuyong Tubiao (1876), in Guo Shuchun ed., Zhongguo Kexue Jishu Dianji Tonghui, Shuxuejuan Volume 5, Henan Jiaoyue Chuban She, 1993, 1035-1038. 李善蘭, 九容 圖表 (1876), 郭書春 編輯, 中國科學技術典籍通彙 5卷 數學卷, 河南敎育出版社, 1993, 1035-1038.

3. Li Yan, Ceyuan Haijing yanjiu licheng kao, in Guo Shuchun ed., Li Yan and Qian Baocong Kexueshi Quanji, Volume 8, Liaoning Jiaoyue Chuban She, 1998, 37-222. 李作, 測圓海鏡研 究歷程考, 郭書春 編輯, 李罯錢寶琮科學史全集 8 卷, 遼寧呚育出版社, 1998, 37-222.

4. Li Zhi, Ceyuan Haijing Xicao, according to Baoshi Zhi Buzu Zhai Chongshu (1248), Li Rui (1798), in Хuxiu Siku Quanshu Volume 1042, p. 297-437, Shanghai Guji Chubanshe, 1995. 李治, 測圓海鏡細草, 鮑氏知不足齋叢書 (1248)，李銳 (1789)，續修四庫全書 1042卷，297-437， 上海古籍出版社, 1995.

5. Liu Yueyun, Ceyuan Haijing Tongshi, Zunjing Shuju, 1896. 劉訔雲，測圓海鏡通釋，尊經書局， 1896.

6. Qian Baocong, A few questions on Ceyuan Haijing (1996), in Guo Shuchun ed., Li Yan and Qian Baocong Kexueshi Quanji Volume 9, Liaoning Jiaoyue Chuban She, 1998, 701-711. 錢寶琮, 有關《測圓海鏡》的幾個問題 (1996), 郭書春 編輯, 李㩔錢寶琮科學史全集 9卷, 遼寧呚育 出版社, 1998, 701-711.

7. YANG Zhaoyun, Jiuyong Yandai, in Xuman Jinglu Suanxue Volume 13-17 (1898). 楊兆輰, 九 容演代, 須曼精盧算學 13-17卷 (1898). 
Appendix 1: List of problems that was treated by Yang in his 6 chapters of work

\begin{tabular}{|c|c|c|c|c|c|c|}
\hline $\mathrm{Q}$ & 大句篇 a1 & 大股篇 b1 & 大弦篇 c1 & 平句篇 a9 & 平弦篇 c9 & 叀句篇 a15 \\
\hline 1 & 大股 $b_{1}$ & 大弦 $\mathrm{c}_{1}$ & 平句 $\mathrm{a}_{9}$ & 叀句 $\mathrm{a}_{15}$ & 叀股 $b_{15}$ & 明句 $a_{14}$ \\
\hline 2 & 大弦 $\mathrm{c}_{1}$ & 平句 $\mathrm{a}_{9}$ & 平弦 $\mathrm{c}_{9}$ & 恵股 $b_{15}$ & 恵弦 $\mathrm{c}_{15}$ & 明股 $b_{14}$ \\
\hline 3 & 平句 $\mathrm{a}_{9}$ & 平弦 $\mathrm{c}_{9}$ & 叀句 $\mathrm{a}_{15}$ & 恵弦 $\mathrm{c}_{15}$ & 明股 $b_{14}$ & 高弦 $\mathrm{c}_{6}$ \\
\hline 4 & 平弦 $\mathrm{c}_{9}$ & 恵句 $a_{15}$ & 恵股 $b_{15}$ & 明股 $b_{14}$ & 明弦 $\mathrm{c}_{14}$ & 虛句 $\mathrm{a}_{13}$ \\
\hline 5 & 惠句 $\mathrm{a}_{15}$ & 恵股 $b_{15}$ & 惠弦 $\mathrm{c}_{15}$ & 明弦 $\mathrm{c}_{14}$ & 高股 $\mathrm{b}_{6}$ & 虛弦 $\mathrm{c}_{13}$ \\
\hline 6 & 叀股 $b_{15}$ & 叀弦 $\mathrm{c}_{15}$ & 明句 $a_{14}$ & 高弦 $\mathrm{c}_{6}$ & 虛句 $\mathrm{a}_{13}$ & 邊股 $\mathrm{b}_{2}$ \\
\hline 7 & 專弦 $\mathrm{c}_{15}$ & 明句 $\mathrm{a}_{14}$ & 明股 $b_{14}$ & 虛股 $b_{13}$ & 虛股 $b_{13}$ & 邊弦 $\mathrm{c}_{2}$ \\
\hline 8 & 明句 $\mathrm{a}_{14}$ & 明股 $b_{14}$ & 明弦 $\mathrm{c}_{14}$ & 虛弦 $\mathrm{c}_{13}$ & 邊股 $\mathrm{b}_{2}$ & 大差句 $\mathrm{a}_{10}$ \\
\hline 9 & 明股 $b_{14}$ & 明弦 $\mathrm{c}_{14}$ & 高股 $b_{6}$ & 邊句 $\mathrm{a}_{2}$ & 邊弦 $\mathrm{c}_{2}$ & 大差股 $b_{10}$ \\
\hline 10 & 明弦 $\mathrm{c}_{14}$ & 高股 $\mathrm{b}_{6}$ & 高弦 $\mathrm{c}_{6}$ & 邊股 $\mathrm{b}_{2}$ & 大差句 $\mathrm{a}_{10}$ & 大差弦 $\mathrm{c}_{10}$ \\
\hline 11 & 高股 $\mathrm{b}_{6}$ & 高弦 $\mathrm{c}_{6}$ & 虛句 $\mathrm{a}_{13}$ & 大差句 $\mathrm{a}_{10}$ & 大差股 $\mathrm{b}_{10}$ & 小差股 $\mathrm{b}_{11}$ \\
\hline 12 & 高弦 $\mathrm{c}_{6}$ & 虛句 $\mathrm{a}_{13}$ & 虛股 $b_{13}$ & 大差股 $b_{10}$ & 小差句 $a_{11}$ & 小差弦 $\mathrm{c}_{11}$ \\
\hline 13 & 虛句 $\mathrm{a}_{13}$ & 虛股 $\mathrm{b}_{13}$ & 虛弦 $\mathrm{c}_{13}$ & 小差句 $\mathrm{a}_{11}$ & 小差弦 $\mathrm{c}_{11}$ & 底句 $\mathrm{a}_{3}$ \\
\hline 14 & 虛股 $b_{13}$ & 虛弦 $\mathrm{c}_{13}$ & 邊股 $\mathrm{b}_{2}$ & 小差股 $b_{11}$ & 底股 $b_{3}$ & 底弦 $\mathrm{c}_{3}$ \\
\hline 15 & 虛弦 $\mathrm{c}_{13}$ & 邊句 $\mathrm{a}_{2}$ & 邊弦 $\mathrm{c}_{2}$ & 底股 $b_{3}$ & 底弦 $\mathrm{c}_{3}$ & 太極股 $b_{12}$ \\
\hline 16 & 邊句 $\mathrm{a}_{2}$ & 邊弦 $\mathrm{c}_{2}$ & 大差句 $\mathrm{a}_{10}$ & 底弦 $c_{3}$ & 太極股 $b_{12}$ & 太極弦 $\mathrm{c}_{12}$ \\
\hline 17 & 邊股 $\mathrm{b}_{2}$ & 大差句 $\mathrm{a}_{10}$ & 大差股 $b_{10}$ & 太極句 $\mathrm{a}_{12}$ & 太極弦 $\mathrm{c}_{12}$ & 斷句 $\mathrm{a}_{17}$ \\
\hline 18 & 邊弦 $\mathrm{c}_{2}$ & 大差弦 $\mathrm{c}_{10}$ & 大差弦 $\mathrm{c}_{10}$ & 太極股 $b_{12}$ & 斷股 $b_{17}$ & 斷股 $b_{17}$ \\
\hline 19 & 大差句 $\mathrm{a}_{10}$ & 小差句 $\mathrm{a}_{11}$ & 小差句 $\mathrm{a}_{11}$ & 斷弦 $\mathrm{c}_{17}$ & 斷弦 $\mathrm{c}_{17}$ & 合句 $a_{16}$ \\
\hline 20 & 大差股 $b_{10}$ & 小差股 $b_{11}$ & 小差股 $\mathrm{b}_{11}$ & 合弦 $\mathrm{c}_{16}$ & 合股 $b_{16}$ & 合股 $b_{16}$ \\
\hline 21 & 大差弦 $\mathrm{c}_{10}$ & 小差弦 $\mathrm{c}_{11}$ & 小差弦 $\mathrm{c}_{11}$ & & & 合弦 $\mathrm{c}_{16}$ \\
\hline 22 & 小差股 $b_{11}$ & 底句 $\mathrm{a}_{3}$ & 底句 $a_{3}$ & & & \\
\hline 23 & 小差弦 $\mathrm{c}_{11}$ & 底股 $b_{3}$ & 底股 $b_{3}$ & & & \\
\hline 24 & 底股 $b_{3}$ & 底弦 $\mathrm{c}_{3}$ & 底弦 $\mathrm{c}_{3}$ & & & \\
\hline 25 & 底弦 $c_{3}$ & 太極句 $a_{12}$ & 太極句 $\mathrm{a}_{12}$ & & & \\
\hline 26 & 太極句 $\mathrm{a}_{12}$ & 太極股 $b_{12}$ & 太極股 $b_{12}$ & & & \\
\hline 27 & 太極股 $b_{12}$ & 太極弦 $\mathrm{c}_{12}$ & 斷句 $\mathrm{a}_{17}$ & & & \\
\hline 28 & 太極弦 $\mathrm{c}_{12}$ & 斷句 $\mathrm{a}_{17}$ & 斷股 $\mathrm{b}_{17}$ & & & \\
\hline 29 & 斷句 $\mathrm{a}_{17}$ & 斷股 $\mathrm{b}_{17}$ & 斷弦 $\mathrm{c}_{17}$ & & & \\
\hline 30 & 斷股 $\mathrm{b}_{17}$ & 斷弦 $\mathrm{c}_{17}$ & 合句 $\mathrm{a}_{16}$ & & & \\
\hline 31 & 斷弦 $\mathrm{c}_{17}$ & 合句 $\mathrm{a}_{16}$ & 合股 $b_{16}$ & & & \\
\hline 32 & 合句 $\mathrm{a}_{16}$ & 合股 $b_{16}$ & 合弦 $\mathrm{c}_{16}$ & & & \\
\hline 33 & 合股 $b_{16}$ & 合弦 $\mathrm{c}_{16}$ & & & & \\
\hline 34 & 合弦 $\mathrm{c}_{16}$ & & & & & \\
\hline
\end{tabular}


Appendix 2: The 21 expressions of cross-multiplication.

\begin{tabular}{|c|c|c|c|}
\hline$(\mathrm{c}+\mathrm{b})$ & $a$ & $(\mathrm{c}+\mathrm{b}-\mathrm{a})$ & $(\mathrm{c}+\mathrm{b}+\mathrm{a})$ \\
\hline$a$ & $(\mathrm{c}-\mathrm{b})$ & $(\mathrm{a}+\mathrm{b}-\mathrm{c})$ & $(\mathrm{c}-\mathrm{b}+\mathrm{a})$ \\
\hline$(\mathrm{c}+\mathrm{b}-\mathrm{a})$ & $(\mathrm{a}+\mathrm{b}-\mathrm{c})$ & $2(\mathrm{c}-\mathrm{a})$ & $2 \mathrm{~b}$ \\
\hline$(\mathrm{c}+\mathrm{b}+\mathrm{a})$ & $(\mathrm{c}-\mathrm{b}+\mathrm{a})$ & $2 \mathrm{~b}$ & $2(\mathrm{c}+\mathrm{a})$ \\
\hline
\end{tabular}$\Leftrightarrow$\begin{tabular}{|c|c|c|c|c|}
$E_{2}$ & $E_{9}$ & $E_{10}$ & $E_{1}$ \\
\hline$E_{9}$ & $E_{15}$ & $E_{13}$ & $E_{11}$ \\
\hline$E_{10}$ & $E_{13}$ & $2 E_{14}$ & $2 E_{6}$ \\
\hline$E_{1}$ & $E_{11}$ & $2 E_{6}$ & $2 E_{3}$ \\
\hline
\end{tabular}

\begin{tabular}{|c|c|}
\hline \hline$E_{2}$ & $E_{9}$ \\
\hdashline$E_{9}$ & $E_{15}$ \\
\hline$E_{2}$ & $E_{9}$ \\
\hdashline$E_{10}$ & $E_{13}$ \\
\hline$E_{2}$ & $E_{9}$ \\
\hdashline$E_{1}$ & $E_{11}$ \\
\hline \hline$E_{9}$ & $E_{15}$ \\
\hdashline$E_{10}$ & $E_{13}$ \\
\hline$E_{9}$ & $E_{15}$ \\
\hdashline$E_{1}$ & $E_{11}$ \\
\hline$E_{10}$ & $E_{13}$ \\
\hdashline$E_{1}$ & $E_{11}$ \\
\hline
\end{tabular}

\begin{tabular}{|c|c|}
\hline$E_{2}$ & $E_{10}$ \\
\hdashline$E_{9}$ & $E_{13}$ \\
\hline$E_{2}$ & $E_{10}$ \\
\hdashline$E_{10}$ & $2 E_{14}$ \\
\hline$E_{2}$ & $E_{10}$ \\
\hdashline$E_{1}$ & $2 E_{6}$ \\
\hline \hline$E_{9}$ & $E_{13}$ \\
\hdashline$E_{10}$ & $2 E_{14}$ \\
\hline$E_{9}$ & $E_{13}$ \\
\hdashline$E_{1}$ & $2 E_{6}$ \\
\hline$E_{10}$ & $2 E_{14}$ \\
\hdashline$E_{1}$ & $2 E_{6}$ \\
\hline
\end{tabular}

\begin{tabular}{|c|c|}
\hline$E_{2}$ & $E_{1}$ \\
\hline$E_{9}$ & $E_{11}$ \\
\hline$E_{2}$ & $E_{1}$ \\
\hdashline$E_{10}$ & $2 E_{6}$ \\
\hline$E_{2}$ & $E_{1}$ \\
\hdashline$E_{1}$ & $2 E_{3}$ \\
\hline$E_{9}$ & $E_{11}$ \\
\hdashline$E_{10}$ & $2 E_{6}$ \\
\hline$E_{9}$ & $E_{11}$ \\
\hdashline$E_{1}$ & $2 E_{3}$ \\
\hline$E_{10}$ & $2 E_{6}$ \\
\hdashline$E_{1}$ & $2 E_{3}$ \\
\hline
\end{tabular}

\begin{tabular}{|c:c|}
\hline \hline$E_{9}$ & $E_{10}$ \\
\hdashline$E_{15}$ & $E_{13}$ \\
\hline$E_{9}$ & $E_{10}$ \\
\hline$E_{13}$ & $2 E_{14}$ \\
\hline$E_{9}$ & $E_{10}$ \\
\hdashline$E_{11}$ & $2 E_{6}$ \\
\hline \hline$E_{15}$ & $E_{13}$ \\
\hdashline$E_{13}$ & $2 E_{14}$ \\
\hline$E_{15}$ & $E_{13}$ \\
\hdashline$E_{11}$ & $2 E_{6}$ \\
\hline$E_{13}$ & $2 E_{14}$ \\
\hdashline$E_{11}$ & $2 E_{6}$ \\
\hline
\end{tabular}

\begin{tabular}{|c:c|}
\hline$E_{9}$ & $E_{1}$ \\
\hline$E_{15}$ & $E_{11}$ \\
\hline \hline$E_{9}$ & $E_{1}$ \\
\hline$E_{13}$ & $2 E_{6}$ \\
\hline$E_{9}$ & $E_{1}$ \\
\hdashline$E_{11}$ & $2 E_{3}$ \\
\hline$E_{15}$ & $E_{11}$ \\
\hdashline$E_{13}$ & $2 E_{6}$ \\
\hline$E_{15}$ & $E_{11}$ \\
\hdashline$E_{11}$ & $2 E_{3}$ \\
\hline$E_{13}$ & $2 E_{6}$ \\
\hdashline$E_{11}$ & $2 E_{3}$ \\
\hline
\end{tabular}

\begin{tabular}{||c:c||}
\hline$E_{10}$ & $E_{1}$ \\
\hdashline$E_{13}$ & $E_{11}$ \\
\hline \hline$E_{10}$ & $E_{1}$ \\
\hdashline $2 E_{14}$ & $2 E_{6}$ \\
\hline$E_{10}$ & $E_{1}$ \\
\hdashline $2 E_{6}$ & $2 E_{3}$ \\
\hline \hline$E_{13}$ & $E_{11}$ \\
\hdashline $2 E_{14}$ & $2 E_{6}$ \\
\hline$E_{13}$ & $E_{11}$ \\
\hdashline $2 E_{6}$ & $2 E_{3}$ \\
\hline $2 E_{14}$ & $2 E_{6}$ \\
\hdashline $2 E_{6}$ & $2 E_{3}$ \\
\hline
\end{tabular}

Those shaded boxes gave duplication of the 21 expressions. For example, the two grids below both represents $(c+b) \times(a+b-c)=a \times(c+b-a)$.

\begin{tabular}{||c:c|}
\hline$E_{2}$ & $E_{9}$ \\
\hdashline$E_{10}$ & $E_{13}$ \\
\hline
\end{tabular}

\begin{tabular}{|c:c|}
\hline$E_{2}$ & $E_{10}$ \\
\hline$E_{9}$ & $E_{13}$ \\
\hline
\end{tabular}


Appendix 3: List of the 24 problems treated by Yang using directly the theorem $a^{2}+b^{2}=c^{2}$.

Using the theorem $a^{2}+b^{2}=c^{2}$ on triangles $\Delta_{11}, \Delta_{1}$ and $\Delta_{16}$ (3 questions)

\begin{tabular}{|c|c|c|}
\hline$\Delta_{11},\left(\mathrm{a}_{1}, \mathrm{~b}_{11}\right)$ & $\Delta_{1},\left(\mathrm{c}_{1}, \mathrm{~b}_{10}\right)$ & $\Delta_{16},\left(\mathrm{a}_{9}, \mathrm{c}_{16}\right)$ \\
\hline$a_{11}=a_{1}-2 r$ & $a_{1}=c_{1}-b_{10}$ & $a_{16}=a_{9}+r$ \\
\hline$b_{11}$ & $b_{1}=b_{10}+D$ & $b_{16}=\frac{r^{2}}{a_{9}}+r$ \\
\hline$c_{11}=a_{1}-b_{11}$ & $c_{1}$ & $c_{16}$ \\
\hline
\end{tabular}

Using the theorem $a_{6}^{2}+b_{6}^{2}=c_{6}^{2}$ on the triangle $\Delta_{6}$, (where $a_{6}=r, 8$ questions)

\begin{tabular}{|l|l|l|l|l|l|l|l|l|}
\hline$\Delta_{6}$ & $\left(\mathrm{~b}_{1}, \mathrm{~b}_{14}\right)$ & $\left(\mathrm{b}_{1}, \mathrm{~b}_{17}\right)$ & $\left(\mathrm{a}_{9}, \mathrm{~b}_{14}\right)$ & $\left(\mathrm{a}_{9}, \mathrm{~b}_{12}\right)$ & $\left(\mathrm{c}_{9}, \mathrm{~b}_{6}\right)$ & $\left(\mathrm{c}_{9}, \mathrm{~b}_{16}\right)$ & $\left(\mathrm{a}_{15}, \mathrm{~b}_{14}\right)$ & $\left(\mathrm{a}_{15}, \mathrm{c}_{16}\right)$ \\
\hline$b_{6}$ & $b_{1}-b_{14}-2 r$ & $b_{17}+r$ & $\frac{r^{2}}{a_{9}}$ & $\frac{r^{2}}{a_{9}}$ & given & $b_{10}-r$ & $\frac{b_{14} r+r^{2}}{a_{15}+r}$ & $\frac{c_{16} r}{a_{9}+r}$ \\
\hline$c_{6}$ & $b_{14}+r$ & $b_{1}-2 r-b_{17}$ & $b_{14}+r$ & $b_{12}$ & $\frac{c_{9} \cdot b_{6}}{r}$ & $\frac{c_{9}\left(b_{16}-r\right)}{r}$ & $b_{14}+r$ & $c_{16}-a_{15}-r$ \\
\hline
\end{tabular}

Using the theorem $a_{9}^{2}+b_{9}^{2}=c_{9}^{2}$ on the triangle $\Delta_{9}$, (where $b_{9}=r, 7$ questions)

\begin{tabular}{|l|l|l|l|l|l|l|l|}
\hline$\Delta_{9}$ & $\left(\mathrm{a}_{1}, \mathrm{a}_{16}\right)$ & $\left(\mathrm{a}_{9}, \mathrm{c}_{14}\right)$ & $\left(\mathrm{c}_{9}, \mathrm{c}_{2}\right)$ & $\left(\mathrm{c}_{9}, \mathrm{c}_{3}\right)$ & $\left(\mathrm{a}_{15}, \mathrm{c}_{6}\right)$ & $\left(\mathrm{a}_{15}, \mathrm{c}_{13}\right)$ & $\left(\mathrm{a}_{15}, \mathrm{~b}_{16}\right)$ \\
\hline$a_{9}$ & $a_{16}-r$ & given & $\frac{c_{9}^{2}+c_{9} r}{c_{2}}$ & $\frac{r^{2}}{c_{3}-c_{9}}$ & $\frac{\left(a_{15}+r\right) r}{c_{6}}$ & $\frac{a_{15}^{2}+a_{15} r}{a_{15}+r-c_{13}}$ & $\frac{r^{2}}{b_{16}-r}$ \\
\hline$c_{9}$ & $a_{1}-a_{16}$ & $\frac{b_{9}^{2}}{a_{9}}+a_{9}-c_{14}$ & given & given & $a_{15}+r$ & $a_{15}+r$ & $a_{15}+r$ \\
\hline
\end{tabular}

Using the theorem $a_{12}^{2}+b_{12}^{2}=c_{12}^{2}$ on the triangle $\Delta_{12}$, (where $a_{12}=c_{9}$ or $a_{15}+r, 6$ questions)

\begin{tabular}{|l|l|l|l|c|c|l|}
\hline$\Delta_{12}$ & $\left(\mathrm{c}_{9}, \mathrm{~b}_{14}\right)$ & $\left(\mathrm{c}_{9}, \mathrm{~b}_{3}\right)$ & $\left(\mathrm{c}_{9}, \mathrm{~b}_{12}\right)$ & $\left(\mathrm{c}_{9}, \mathrm{c}_{12}\right)$ & $\left(\mathrm{c}_{9}, \mathrm{c}_{17}\right)$ & $\left(\mathrm{a}_{15}, \mathrm{~b}_{12}\right)$ \\
\hline$a_{12}$ & $c_{9}$ & $c_{9}$ & $c_{9}$ & $c_{9}$ & $c_{9}$ & $a_{15}+r$ \\
\hline$b_{12}$ & $\left(b_{14}+r\right)$ & $\left(b_{3}-r\right)$ & given & $\frac{c_{12} \cdot r}{c_{9}}$ & $c_{17}+c_{9}$ & given \\
\hline$c_{12}$ & $\frac{c_{9} \cdot b_{14}}{r}+c_{9}$ & $\frac{b_{3} \cdot c_{9}}{r}-c_{9}$ & $\frac{c_{9} \cdot b_{12}}{r}$ & given & $\frac{c_{9} \cdot c_{17}+c_{9}^{2}}{r}$ & $\frac{b_{12} \cdot a_{15}}{r}+b_{12}$ \\
\hline
\end{tabular}


Appendix 4: List of problems of the 6 cases treated by Yang in using the principle of interchanging triangles and events

\begin{tabular}{|l|l|l|l|l|l|l|}
\hline Cases & $a_{1}$ & $b_{1}$ & $c_{1}$ & $a_{9}$ & $c_{9}$ & $a_{15}$ \\
\hline Number of questions & 20 & 14 & 18 & 5 & 2 & 6 \\
\hline
\end{tabular}

\begin{tabular}{|l|l|l|l|}
\hline \multicolumn{2}{|c|}{$a_{1}$ (total 20 questions using the principle) } & 19 & $a_{1} \cdot(c-b+a)_{10}=a_{10} \cdot(c-b+a)_{1}$ \\
\hline 6 & $(c-b)_{1} \cdot a_{11}=(c-b)_{11} \cdot a_{1}$ & 20 & $(c-b+a)_{10} \cdot b_{13}=(c-b+a)_{13} \cdot b_{10}$ \\
\hline 7 & $(a+b+c)_{9} \cdot(b-a)_{11}=(a+b+c)_{11} \cdot(b-a)_{9}$ & 21 & $(a+b+c)_{12} \cdot(c+b-a)_{1}=(a+b+c)_{1} \cdot(c+b-a)_{12}$ \\
\hline 9 & $(a+b-c)_{6} \cdot(c-a)_{1}=(a+b-c)_{1} \cdot(c-a)_{6}$ & 23 & $c_{1} \cdot(b+c)_{11}=c_{11} \cdot(b+c)_{1}$ \\
\hline 10 & $c_{1} \cdot 2 a_{14}=c_{14} \cdot 2 a_{1}$ & 24 & $(a+b-c)_{6} \cdot(a+c)_{1}=(a+b-c)_{1} \cdot(a+c)_{6}$ \\
\hline 11 & $(a+b-c)_{6} \cdot b_{1}=(a+b-c)_{1} \cdot b_{6}$ & 25 & $a_{2} \cdot c_{1}=a_{1} \cdot c_{2}$ \\
\hline 12 & $(a+b-c)_{6} \cdot c_{1}=(a+b-c)_{1} \cdot c_{6}$ & 27 & $a_{6} \cdot(a+c)_{1}=a_{1} \cdot(a+c)_{6}$ \\
\hline 15 & $(c-b)_{13} \cdot(a+b-c)_{1}=(c-b)_{1} \cdot(a+b-c)_{13}$ & 28 & $c_{1} \cdot(a+b)_{12}=c_{12} \cdot(a+b)_{1}$ \\
\hline 16 & $a_{2} \cdot(c-b+a)_{9}=a_{9} \cdot(c-b+a)_{2}$ & 31 & $(a+b-c)_{1} \cdot(a+b+c)_{17}=(a+b-c)_{17} \cdot(a+b+c)_{1}$ \\
\hline 17 & $(c-b+a)_{2} \cdot b_{1}=(c-b+a)_{1} \cdot b_{2}$ & 34 & $(a+b+c)_{16} \cdot c_{1}=(a+b+c)_{1} \cdot c_{16}$ \\
\hline 18 & $c_{9} \cdot(c-b+a)_{2}=c_{2} \cdot(c-b+a)_{9}$ & & \\
\hline
\end{tabular}

\begin{tabular}{|l|l|l|l|}
\hline \multicolumn{2}{|c|}{$b_{1}$ (total 14 questions using the principle) } \\
\hline 5 & $b_{1} \cdot(a+b+c)_{15}=b_{15} \cdot(a+b+c)_{1}$ & 16 & $b_{2} \cdot c_{1}=b_{1} \cdot c_{2}$ \\
\hline 6 & $(c-b)_{1} \cdot(a+b+c)_{12}=(c-b)_{12} \cdot(a+b+c)_{1}$ & 22 & $a_{6} \cdot(a+b+c)_{3}=a_{3} \cdot(a+b+c)_{6}$ \\
\hline 9 & $(a+b-c)_{14} \cdot(a+b)_{1}=(a+b-c)_{1} \cdot(a+b)_{14}$ & 26 & $(c-a)_{6} \cdot a_{1}=(c-a)_{1} \cdot a_{6}$ \\
\hline 10 & $b_{6} \cdot(a+b+c)_{1}=b_{1} \cdot(a+b+c)_{6}$ & 27 & $(a+b-c)_{12} \cdot c_{1}=(a+b-c)_{1} \cdot c_{12}$ \\
\hline 13 & $b_{13} \cdot(a+b+c)_{1}=b_{1} \cdot(a+b+c)_{13}$ & 28 & $b_{9} \cdot(b-a)_{1}=b_{1} \cdot(b-a)_{9}$ \\
\hline 14 & $(a+b-c)_{1} \cdot(a+b+c)_{12}=(a+b-c)_{12} \cdot(a+b+c)_{1}$ & 30 & $(a+b+c)_{17} \cdot c_{1}=(a+b+c)_{1} \cdot c_{17}$ \\
\hline 15 & $a_{2} \cdot(a+b+c)_{15}=a_{15} \cdot(a+b+c)_{2}$ & 33 & $c_{1} \cdot(a+b+c)_{16}=c_{16} \cdot(a+b+c)_{1}$ \\
\hline
\end{tabular}

\begin{tabular}{|l|l|l|l|}
\hline \multicolumn{2}{|c|}{$c_{1}$ (total 18 questions using the principle) } \\
\hline 1 & $c_{12} \cdot(a+b)_{1}=c_{1} \cdot(a+b)_{12}$ & 16 & $a_{10} \cdot(c-b+a)_{14}=a_{14} \cdot(c-b+a)_{10}$ \\
\hline 2 & $a_{2} \cdot(a+c)_{15}=a_{15} \cdot(a+c)_{2}$ & 18 & $(c-b+a)_{12} \cdot c_{10}=(c-b+a)_{10} \cdot c_{12}$ \\
\hline 3 & $a_{12} \cdot c_{15}=a_{15} \cdot c_{12}$ & 21 & $(c-b+a)_{11} \cdot c_{12}=(c-b+a)_{12} \cdot c_{11}$ \\
\hline 5 & $(a+c)_{15} \cdot a_{2}=(a+c)_{2} \cdot a_{15}$ & 24 & $b_{3} \cdot c_{12}=b_{12} \cdot c_{3}$ \\
\hline 7 & $b_{3} \cdot c_{14}=b_{14} \cdot c_{3}$ & 27 & $a_{9} \cdot b_{17}=a_{17} \cdot b_{9}$ \\
\hline 8 & $b_{14} \cdot c_{9}=c_{14} \cdot b_{9}$ & 28 & $b_{9} \cdot a_{16}=b_{16} \cdot a_{9}$ \\
\hline 9 & $c_{12} \cdot(a+b+c)_{1}=c_{1} \cdot(a+b+c)_{12}$ & 29 & $c_{10} \cdot(c-b+a)_{12}=c_{12} \cdot(c-b+a)_{10}$ \\
\hline 13 & $c_{1} \cdot(a+b)_{13}=c_{13} \cdot(a+b)_{1}$ & 30 & $a_{16} \cdot b_{17}=a_{17} \cdot b_{16}$ \\
\hline 14 & $b_{9} \cdot(a+c)_{2}=b_{2} \cdot(a+c)_{9}$ & 32 & $c_{16} \cdot(a+b)_{1}=c_{16} \cdot(a+b)_{1}$ \\
\hline
\end{tabular}




\begin{tabular}{|c|l|c|l|}
\hline \multicolumn{2}{|c|}{$a_{9}$ (total 5 questions using the principle) } \\
\hline 7 & $(a+b+c)_{13} \cdot(a+c)_{14}=(a+b+c)_{14} \cdot(a+c)_{13}$ & 16 & $(a+c)_{9} \cdot a_{12}=(a+c)_{12} \cdot a_{9}$ \\
\hline 8 & $c_{16} \cdot(a+b-c)_{13}=c_{13} \cdot(a+b-c)_{16}$ & 19 & $(c+b-a)_{17} \cdot c_{11}=(c+b-a)_{11} \cdot c_{17}$ \\
\hline 13 & $a_{15} \cdot(a+b+c)_{9}=a_{9} \cdot(a+b+c)_{15}$ & & \\
\hline
\end{tabular}

\begin{tabular}{|l|l|l|l|}
\hline \multicolumn{3}{|c|}{$c_{9}$ (total 2 questions using the principle) } \\
\hline 8 & $a_{9} \cdot \mathrm{b}_{2}=a_{2} \cdot \mathrm{b}_{9}$ & 11 & $(c-b)_{9} \cdot \mathrm{b}_{1}=(c-b)_{1} \cdot \mathrm{b}_{9}$ \\
\hline
\end{tabular}

\begin{tabular}{|l|l|l|l|}
\hline \multicolumn{2}{|l|}{$a_{15}$ (total 6 questions using the principle) } \\
\hline 4 & $a_{15} \cdot(\mathrm{b}+\mathrm{c})_{9}=a_{9} \cdot(\mathrm{b}+\mathrm{c})_{15}$ & 11 & $b_{9} \cdot \mathrm{c}_{15}=b_{15} \cdot \mathrm{c}_{9}$ \\
\hline 6 & $a_{15} \cdot(\mathrm{b}+\mathrm{c})_{9}=a_{9} \cdot(\mathrm{b}+\mathrm{c})_{15}$ & 12 & $c_{15} \cdot \mathrm{a}_{11}=c_{11} \cdot \mathrm{a}_{15}$ \\
\hline 8 & $a_{15} \cdot(\mathrm{b}+\mathrm{c})_{9}=a_{9} \cdot(\mathrm{b}+\mathrm{c})_{15}$ & 18 & $a_{15} \cdot(\mathrm{b}+\mathrm{c})_{9}=a_{9} \cdot(\mathrm{b}+\mathrm{c})_{15}$ \\
\hline
\end{tabular}

